Bangladesh J. Pl. Breed. Genet., 24(2): 25-30, 2011

\title{
GENETIC DIVERSITY IN RICE (Oryza sativa L.) LANDRACES OF HILLY AREAS IN BANGLADESH
}

\author{
Genetic Resources Division \\ Bangladesh Rice Research Institute \\ Joydebpur, Gazipur 1701, Bangladesh
}

M. A. Siddique, M. Z. Islam, M. Khalequzzaman and M. S. Ahmed

\begin{abstract}
Genetic diversity in 38 traditional local rice genotypes grown as Jhum in the hilly areas was studied under rainfed condition through Mahalanobis $\mathrm{D}^{2}$ statistic for grain yield and yield contributing characters. The genotypes were grouped into five clusters. The inter-cluster distances were higher than intra-cluster distances indicating wider genetic diversity among the clusters. The intra-cluster distances were lower in all the cases reflecting homogeneity of the genotypes within the clusters. The cluster $\mathrm{V}$ contained the highest number of genotypes (12) and the cluster I and III contained the lowest (5). The highest intra-cluster distance was noticed for the cluster III and lowest for cluster I. The highest intercluster distance was observed between cluster I and III followed by cluster II and III, cluster III and IV and the lowest between cluster II and IV. Regarding inter-cluster distance, the genotypes of cluster III showed high genetic distance from all other clusters. The genotypes from cluster III could be hybridized with the genotypes of other clusters for producing transgressive segregants. Based on positive value of vector 1 and vector 2, flag leaf length, flag leaf width, days to $50 \%$ flowering, days to maturity, unfilled grain panicle ${ }^{-1}$, grain length and grain length breath ratio had maximum contribution towards genetic divergence. The highest cluster means for plant height, filled grains panicle ${ }^{-1}$ and yield were obtained from cluster III. The highest flag leaf width, days to $50 \%$ flowering, unfilled grain panicle ${ }^{-1}$, grain length, grain breath and grain length breath ratio while the lowest mean value for yield were found in cluster I. The lowest days to $50 \%$ flowering and maturity, and highest mean value for 1000-grain weight were found in cluster IV. Therefore, more emphasis should be given on cluster I and cluster III for selecting genotypes as parents for crossing with the genotypes of cluster IV which could produce new recombinants with desired traits.
\end{abstract}

Key words: Genetic diversity, $\mathrm{D}^{2}$ analysis, cluster analysis, rice (Oryza sativa $\left.\mathrm{L}\right)$

\section{INTRODUCTION}

Rice is considered as a major cereal crop in Bangladesh as it constitutes $96 \%$ of the total food grain (rice \& wheat) production (Anonymous, 2008). Although Bangladesh is now on the verge of attaining self sufficiency in cereal production, there is still a large gap between the production and increasing demand for food.

The Chittagong Hill Tract (CHT) has an area of 13,180 km, making up approximately $10 \%$ of the total area of Bangladesh. Agriculture remains the main form of livelihood for CHT residents. Rice, with an agricultural yield of $0.90 \mathrm{Mt}$, is grown on $43.3 \%$ of the total cultivated land $(0.19 \mathrm{M}$ ha) (Ullah, 2002). The poor yield of rice is due lack of high yielding varieties suitable for hilly areas. The farmer usually grows low 
yielding local varieties. However, these local varieties have much potential genepool to generate high yielding progenies when engaged in breeding program.

Genetic diversity is a powerful tool to determine the genetic discrimination among the genotypes which is used to select appropriate parents for hybridization to develop high yielding variety (Bhatt, 1970). With the development of advanced biometrical techniques such as multivariate analysis based on the Mahalanobis (1936) statistics, quantification of divergence among the biological population and assessing the relative contribution of different components to the total divergence at intra and intercluster levels have now become possible. Such a study also permits to select the genetically diverse parents to obtain the desirable recombinant in the segregating generations upon crossing. Hybridization is a common practice for combining the desirable characters of two or more lines or varieties into a single variety. In several cases, the progenies become far superior to the parents in vigor. Inclusion of more diverse parents (within a limit) is believed to increase the chances for obtaining stronger heterosis and gives broad spectrum of variability in segregating generations (Joshi and Dhawan, 1966; Ananda and Murty, 1968). In addition, crossing in moderately diverse parents also showed maximum heterosis (Chauhan and Singh, 1982). The necessity of principal component analysis (PCA), principal coordinate analysis (PCO), nonhierarchical clustering and canonical vector analysis (CVA) for measuring the degree of divergence has been established by several investigators in rice and other crops (Selvakumar et al., 1989; De et al., 1988; Pathan et al., 1993).

About 8700 rice germplasm have been preserved in BRRI gene bank. But information on genetic divergence in hilly germplasm is scanty. The present study was, therefore undertaken to assess the extent of genetic diversity in 38 traditional rice varieties grown as Jhum in hilly areas. This will help in classifying those into clusters to select genotypes as prospective parents to develop transgressive segregants which will be ultimately used for developing modern variety suitable for hilly areas as well as conserve soil by decreasing soil erosion caused by Jhum cultivation.

\section{MATERIALS AND METHODS}

Thirty eight rice genotypes of hilly areas that are grown as jhum selected from the germplasm bank of Bangladesh Rice Research Institute (BRRI), Gazipur were grown under rainfed condition in 2011. The trial was conducted in a randomized complete block design with three replications. Seeds were sown by broadcast method and plant populations were maintained at $25 \mathrm{~cm}$ and $20 \mathrm{~cm}$ space between rows and plants, respectively. Fertilizers were applied @ 80:60:40: $12 \mathrm{~kg} \mathrm{~N}, \mathrm{P}, \mathrm{K}$ and S per hectare. All the fertilizers except $\mathrm{N}$ were applied at final land preparation. Nitrogen was applied in three equal splits, at 15 days after sowing (DAS), at 35 DAS and just before flowering. Intercultural operations and pest control measures were done as and when necessary. At maturity, grain yield (g/hill) was taken and adjusted at $14 \%$ moisture level. Ten hills from each entry were randomly selected for recording data on flag leaf length $(\mathrm{cm})$, flag leaf width $(\mathrm{cm})$, plant height $(\mathrm{cm})$, days to $50 \%$ flowering, days to maturity, panicle length $(\mathrm{cm})$, grain length $(\mathrm{mm})$, grain breadth $(\mathrm{mm})$, length-breadth ratio, 1000 grain weight $(\mathrm{g})$, filled grains panicle ${ }^{-1}$, unfilled grains panicle ${ }^{-1}$ and yield hill ${ }^{-1}(\mathrm{~g})$. The data were analyzed following principal component analysis (PCA) and Mahalanobis's (1936) generalized distance $\left(\mathrm{D}^{2}\right)$ extended by Rao (1952). Intra and inter cluster distances were calculated by the method of Singh and Chaudhury (1985). All statistical analyses were carried out using Genstat 5.5. 


\section{RESULTS AND DISCUSSION}

Analysis of variance showed significant differences among the 38 genotypes for all of the 13 characters under study indicating the presence of notable genetic variability among the genotypes. The principal component analysis showed that the first two components accounted for $77.91 \%$ of the total variation.

Based on the degree of divergence 38 genotypes were grouped into five clusters on the basis of cluster analysis (Table1). Maximum 12 entries were grouped into the cluster V followed by eight in cluster II and IV, and five in cluster I and III.

Table 1. Distribution of 38 rice genotypes in different clusters

\begin{tabular}{c|c|c|c}
\hline $\begin{array}{c}\text { Cluster } \\
\text { no. }\end{array}$ & $\begin{array}{c}\text { No. of } \\
\text { genotypes }\end{array}$ & $\begin{array}{c}\text { BRRI Collection no. of Genotypes } \\
\text { (New collection under KGF project) }\end{array}$ & \multicolumn{1}{c}{ Name of the Genotypes } \\
\hline I & 5 & $85,88,111,184,109$ & $\begin{array}{l}\text { Kamarang, Plokapora binni, } \\
\text { Baijja, Silongma (Suli), Suri } \\
\text { dhan, }\end{array}$ \\
II & 8 & $82,90,92,146,154,165,173,107$ & $\begin{array}{l}\text { Noli, Lal binni, Ranga binni, } \\
\text { Patri, Rengui dhan, Gurli, } \\
\text { Abdullah, Ranga binni, } \\
\text { Gul galong, Kiron lal, } \\
\text { Magumai malok (Gura sada), } \\
\text { Chorui, Rangun jhuri }\end{array}$ \\
III & 5 & $99,112,114,166,182$ & $\begin{array}{l}\text { Company, Kaborok, } \\
\text { Bandarnok binni, Napidi, } \\
\text { Maiosa, Bandarnok beni, } \\
\text { Khulua, Iakedi, } \\
\text { Guri dhan, Galon, Maloti, } \\
\text { Chorui lal, Lankapura, } \\
\text { Tomlong, Kanoktara, Uttrasha } \\
\text { beni, 33 no. dhan, Narikel } \\
\text { chhari, Guligh dhan, Maloti }\end{array}$ \\
IV & 8 & $80,81,86,117,124,138,174,175$ & \\
& & & $83,84,89,94,98,100,118,140$, \\
V & 12 & $144,155,177,101$ & \\
& & &
\end{tabular}

Intra and inter-cluster distance are presented in Table 2. All the inter-cluster distances were larger than the intra-cluster distant indicating presence of wider diversity among genotypes of distance groups. All germplasm are traditional but they showed high variability among themselves which was revealed from the results of intra and intercluster distance values. The highest intra cluster value in cluster III (1.0998) and the highest inter-cluster value between cluster I and III (12.222) clearly indicated variability's in the germplasm of cluster III. The higher variation among the genotypes in cluster III contributed to higher inter cluster distance with other cluster. However, intracluster distances were low in all the five clusters with the range of 0.6254 in cluster I to 1.0998 in cluster III which indicated homogeneous nature of the genotypes within the clusters. The results were supported by the findings of Iftekharuddaula et al. (2002) in rice. The inter-cluster distances ranged from 3.828 to 12.222 and PCA scores also indicated a high degree of genetic diversity among the genotypes. Regarding inter-cluster distance, cluster III showed maximum genetic distance from cluster I (12.222) followed from cluster II (10.060) and from cluster IV (8.789). It is obvious that in all the cases cluster III produced the highest inter-cluster distances with other clusters suggesting wide diversity of the genotypes within cluster III with the genotypes of other clusters and the genotypes in these clusters could be used as parents in hybridization program for 
getting transgressive segregants (Saini and Kaiker, 1987). Moderate inter-cluster distance was observed between cluster I and IV (7.235) followed by cluster I and V (6.704), cluster III and V (6.242). The minimum inter-cluster diversity was observed between cluster II and IV (3.828), cluster IV and V (3.867), cluster II and V (4.272) and cluster I and II (5.300) indicating that the genotypes of these clusters were genetically closed.

Table 2. Intra (bold) and inter-cluster distances $\left(\mathrm{D}^{2}\right)$ for 38 hilly rice genotypes

\begin{tabular}{c|c|c|c|c|c}
\hline Cluster & I & II & III & IV & V \\
\hline I & $\mathbf{0 . 6 2 5 4}$ & 5.300 & 12.222 & 7.235 & 6.704 \\
II & & $\mathbf{0 . 7 0 5 9}$ & 10.060 & 3.828 & 4.272 \\
III & & & $\mathbf{1 . 0 9 9 8}$ & 8.789 & 6.242 \\
IV & & & & $\mathbf{0 . 7 1 1 3}$ & 3.867 \\
V & & & & & $\mathbf{0 . 7 5 7 0}$ \\
\hline
\end{tabular}

The highest cluster means for plant height, grains panicle ${ }^{-1}$ and yield were obtained from cluster III. The highest flag leaf width, days to 50\% flowering, unfilled grain panicle ${ }^{-1}$, grain length, grain breath and grain length breadth ratio while the lowest mean value for yield were found in cluster I. The lowest days to $50 \%$ flowering and maturity, and highest mean value for 1000-grain weight grain breadth were found in cluster IV (Table 3 ).

Mean performance of different clusters for the characters revealed that dwarf stature, short growth duration, lower panicle length and moderate yielding varieties were aggregated into cluster IV whereas genotypes with panicle length and other second highest yield contributing characters (tall plant height, filled grains panicle ${ }^{-1}$ ) and yield were reported by the cluster $\mathrm{V}$.

The maximum numbers of genotypes with desirable characters were congregated in cluster III and as a result higher yield ( $7.37 \mathrm{~g} /$ hill) was obtained in this cluster. But it was interesting that in all cases cluster III produced the highest inter-cluster value with all other clusters. Therefore, the genotypes of cluster III can be used as one parent in the crossing program with the genotypes from all other clusters to produce high yielding genotypes.

Table 3. Cluster means for thirteen characters of 38 Jhum rice genotypes

\begin{tabular}{l|c|c|c|c|c}
\hline \multirow{2}{*}{ Characters } & \multicolumn{4}{|c}{ Cluster Number } \\
\cline { 2 - 6 } & I & II & III & IV & V \\
\hline Flag leaf length (cm) & 38.26 & 38.57 & 38.01 & 34.60 & 36.58 \\
Flag leaf width (cm) & 1.72 & 1.49 & 1.60 & 1.55 & 1.52 \\
Plant height (cm) & 88.09 & 83.85 & 99.03 & 84.27 & 92.71 \\
Days to 50\% flowering & 131.40 & 131.18 & 125.91 & 124.00 & 127.80 \\
Days to maturity & 159.53 & 159.59 & 154.58 & 149.95 & 156.33 \\
Panicle length (cm) & 24.17 & 23.35 & 24.58 & 21.77 & 24.61 \\
Filled grains/panicle (no.) & 39.59 & 50.33 & 85.86 & 46.78 & 60.23 \\
Unfilled grains/panicle (no.) & 35.95 & 14.92 & 17.01 & 13.46 & 16.63 \\
Grain length (mm) & 10.06 & 9.22 & 6.66 & 8.44 & 7.79 \\
Grain breadth (mm) & 2.00 & 2.00 & 1.85 & 2.12 & 1.93 \\
Length-breath ratio & 5.03 & 4.65 & 3.58 & 4.01 & 4.03 \\
1000 grain weight (g) & 22.92 & 23.21 & 18.95 & 23.83 & 19.98 \\
Yield/hill (g) & 3.03 & 4.50 & 7.37 & 5.15 & 6.64 \\
\hline
\end{tabular}


Joshi and Dhawan (1966) reported that inclusion of more diverse parents (within a limit) is believed to increase the chances for obtaining stronger heterosis and gives broad spectrum of variability in segregating generations. Therefore, more emphasis should be given in selecting genotypes as parents from cluster III and I for crossing with the genotypes of cluster IV, which may produce new recombinants with desired traits. Cluster I had the highest cluster mean value for unfilled grains panicle ${ }^{-1}$ and lower filled grains panicle ${ }^{-1}$ which had negative effect on mean value of yield. It was also noticed that yield performance in five clusters was more variable. The results reflected that all these varieties were genetically distant from each other.

Contributions of the characters towards divergence are presented in Table 4. The canonical vector analysis revealed that the vectors (vector I and II) for flag leaf length, flag leaf width, days to $50 \%$ flowering, days to maturity, unfilled grain panicle ${ }^{-1}$, grain length and grain length breadth ratio were positive. Such result indicated that these seven characters contributed maximum towards divergence. It is interesting that the greater divergence in the materials under study was due to these seven characters, which will offer a good scope for improvement of yield through rational selection of parents.

Table 4. Relative contributions of the thirteen characters to the total divergence in Jhum rice

\begin{tabular}{lcc}
\hline Trait & Vector 1 & Vector 2 \\
\hline Flag leaf length $(\mathrm{cm})$ & 0.0785 & 0.3521 \\
Flag leaf width $(\mathrm{cm})$ & 0.1215 & 0.0027 \\
Plant height $(\mathrm{cm})$ & -0.3146 & 0.2762 \\
Days to 50\% flowering & 0.1608 & 0.4274 \\
Days to maturity & 0.1002 & 0.4773 \\
Panicle length (cm) & -0.1403 & 0.3479 \\
Filled grains/panicle (no.) & -0.3803 & 0.1254 \\
Unfilled grains/panicle (no.) & 0.2292 & 0.2222 \\
Grain length (mm) & 0.4626 & 0.0658 \\
Grain breadth (mm) & 0.2034 & -0.3628 \\
Length-breadth ratio & 0.3942 & 0.1864 \\
1000 grain weight (g) & 0.3329 & -0.1737 \\
Yield/hill (g) & -0.3252 & -0.0480 \\
\hline
\end{tabular}

It is assumed that, maximum amount of heterosis would be manifested in cross combinations involving the parents belonging to most divergent clusters. However, for a practical plant breeder, the objective is not only to have high heterosis but also to achieve high level of production reducing the growth duration. In the present study the maximum distances was observed between cluster I and III. Thereby, considering yield/hill, filled grains panicle ${ }^{-1}$, 1000-grain weight, and grain length breadth ratio, crosses involving cluster III and cluster I might exhibit high heterosis for yield. Again, considering growth duration, and plant height, crosses between cluster II and IV might exhibit higher heterosis for earliness and dwarf stature. Mian and Bahl (1989) reported that the parents separated by inter-cluster of medium magnitude generally showed higher heterosis in chickpea. Similar findings also reported by Habib et al. (2005) for rice. Keeping this view in mind, it appeared that the crosses between the genotypes/parents of cluster I and cluster III, cluster II and cluster IV would exhibit high heterosis as well as higher level of yield potential. Therefore, the genotypes under cluster I and cluster III, cluster II and cluster IV might be selected for future breeding program. 


\section{REFERENCES}

Anand, I. J. and B. R. Murty. 1968. Genetic divergence and hybrid performance in linseed. Indian J. Genet. Pl. Breed. 28: 178-185.

Anonymous, 2008. Statistical Yearbook of Bangladesh. Bangladesh Bureau of Statistics. Ministry of Planning, Govt. of Bangladesh.

Bhatt, G. M. 1970. Multivariate analysis approach to selection of parents of hybridization aiming at yield improvement in self-pollinated crops. Aust. J. Agric. Res. 21: 1-7.

Chauhan, V. S. and B. B. Singh. 1982. Heterosis and genetic variability in relation to genetic divergence in soybean. Indian J. Genet. Pl. Breed. 42(2): 324 - 328.

De, R. N., R. Seetharaman, M. K. Sinha and S. P. Banerjee. 1988. Genetic divergence in rice. Indian J. PI. Breed. Genet. 48(2): 189-194.

Habib, S. H., M. K. Bashar, M. Khalequzzaman, M. S. Ahmed and E. S. M. H. Rashid. 2005. Genetic analysis and morpho-physiological selection criteria for traditional Biroin Bangladesh rice germplasms. J. Biol. Sci. 5(3): 315-318.

Iftekharuddaula, K. M., K. Akter, M. K. Bashar and M. R. Islam. 2002. Genetic parameters and cluster analysis of analysis of panicle traits in irrigated rice. Bangladesh J. PI. Breed. Genet. 15(1): 49-55

Joshi, A. B. and N. L. Dhawan. 1966. Genetic improvement of yield with special reference to self fertilizing crops. Indian J. Genet. PI. Breed. 26A: 101-113.

Mahalanobis, P. C. 1936. On the generalized distance in Statistics. Proc. Natl. Inst. Sci., India. 2: 49-55.

Mian, M. A. K. and P. N. Bahi. 1989. Genetic divergence and hybrid performance in chickpea. Indian J. Genet. 49(1): 119-124.

Rao, C. R. 1952. Advanced Statistical method in biometries research. John Wiley and Sons. New York.

Pathan, M. S., E. Haque, N. M. Miah and M. A. A. Miah. 1993. Genetic diversity in rice varieties released and recommended by BRRI. Bangladesh J. Bot. 22(2): 161-166.

Saini, H. C. and U. S. Kaicker. 1987. Genetic diversity in opium poppy. Indian J. Genet. 47: 291-296.

Selvakumar, K. S., G. Soundrapandian and A. Amirthadevarathinam. 1989. Genetic divergence for yield and yield components in cold tolerant rice. Madras Agril. J. 76(12): 688-694.

Singh, R. K. and B. D. Chaudhury. 1985. Biometrical methods in quantitative genetic analysis. Kalayoni publishers. New Delhi.

Ullah, M. 2002. Mountain issues and communities in Chittagong Hill Tracts of angladesh. Policy brief no. 3, South AsiaWatch on Trade, Economics \& Environment (SAWTEE), Kathmandu. 